\title{
The Effect of Concurrent Exercise Order (Resistance and Endurance) on Lipid Profile, Leptin Serum and Insulin Resistance Index in Overweight Women
}

\author{
Mehdi Hakimi $^{1 *}$ and Maryam Ali-Mohammadi ${ }^{2}$ \\ ${ }^{1}$ Department of Physical Education \& Sport Science, Marivan Branch, Islamic Azad University, Marivan, Iran \\ ${ }^{2}$ Department of Physical Education \& Sport Science, Sanandaj Branch, Islamic Azad University, Sanandaj, Iran
}

*Corresponding author: Mehdi Hakimi, Ph.D, Assistant Professor of Exercise Physiology of Cardiovascular and Respiration, Department of Physical Education \& Sport Science, Marivan Branch, Islamic Azad University, Marivan, Iran, Tel: +989189123757, Email: Mehdihakimi66@yahoo.com

\begin{abstract}
Purpose: The purpose of this study was the effect of concurrent exercise order on lipid profile, leptin serum and insulin resistance index in non-athlete overweight women.

Methods: Thirty female students (age $=23.2 \pm 2.4$ year, BMI $=27.87 \pm 1.3 \mathrm{~kg} / \mathrm{m}^{2}$ ) volunteered to participate in this study and were randomly divided into three groups of 10 people taking the Concurrent Endurance-Resistance (CER), Concurrent Resistance- Endurance (CRE) and Control (C). Two exercise groups performed the same concurrent exercise, but the order of endurance and resistance exercise were different in two groups. Fasting blood samples were collected before and after completion of the exercise. The paired sample t-test was used to determine differences within a group, and variation between groups analysis of variance (ANOVA) and LSD were used.
\end{abstract}

Results: The implementation of a concurrent exercise session in two exercise groups except for the indicators of HDL that there was no significant change, caused to significantly decreases in TC, TG, LDL, insulin, insulin resistance indices and leptin serum that this rate of changes was significant compared with the control group. But no significant difference was observed between implementation of two methods of concurrent exercise. In addition, the control group did not change significantly in none of the variables.

Conclusion: Although the implementation one session of a combination of resistance and endurance exercise improves lipid profile, insulin resistance index and leptin serum but the effectiveness of two methods of concurrent endurance-resistance and resistance-endurance were similar.

\section{Keywords}

Endurance exercise, Resistance exercise, Lipid profile, Leptin, Overweight

\section{Introduction}

Obesity and overweight are the most important relevant factors involved the development of Cardiovascular Disease (CVD). CVD is one of the leading causes of mortality in the world; therefore, identification of cardiovascular risk factors is important to prevent disease progression and reduce medical and treatment expenses [1]. There are many risk factors associated with $C V D$, that the effects of leptin, insulin resistance, and lipid profile are important $[2,3]$. Leptin is a cytokine released by adipose tissue that regulates the appetite and represents a considerable factor in the development of obesity [4]. The studies showed that the leptin concentrations were positively correlated with body fat in obese and normal-weight adults and it seems that with further storage of triglycerides in adipose tissue, the release of leptin increases $[5,6]$. Besides, there is a positive association between CVD and lipid profile [7]. The lipid profile includes Total Cholesterol (TC), triglyceride (TG), High-Density Lipoprotein-Cholesterol (HDL-C), Low-Density Lipoprotein-Cholesterol (LDL-C) and very Low-Density Lipoprotein-Cholesterol (VLDL-C) [8]. For the purpose of CVD risk reduction, management of TC,

Citation: Hakimi M, Ali-Mohammadi M (2019) The Effect of Concurrent Exercise Order (Resistance and Endurance) on Lipid Profile, Leptin Serum and Insulin Resistance Index in Overweight Women. Int J Sports Exerc Med 5:149. doi.org/10.23937/2469-5718/1510149

Accepted: October 15, 2019; Published: October 17, 2019

Copyright: (c) 2019 Hakimi M, et al. This is an open-access article distributed under the terms of the Creative Commons Attribution License, which permits unrestricted use, distribution, and reproduction in any medium, provided the original author and source are credited. 
LDL-C, TG, and HDL-C is of clinical benefit [9].

As mentioned previously, insulin resistance is one of the cardiovascular risk factors. Insulin resistance is a pathological condition in which body cells fail to respond normally to the insulin, glucose absorption is impaired, and as a result, the amount of glucose in the bloodstream increases [10] which leads to different diseases, such as CVD. Of course, there were several molecular mechanisms contribute to the relation between insulin resistance and CVD, that can be mentioned the role of insulin resistance in atherosclerosis development, vascular function, hypertension and macrophage accumulation [11].

Most studies indicate that regular exercise training leads to beneficial effects on cardiovascular indices such as blood lipids, insulin resistance and leptin concentration [12,13]; however, the duration and intensity of exercises should be enough. Sheikholeslami-Vatani, et al. reported that concurrent training is the best method to enhance health level, improve physical fitness and decrease cardiovascular risk factors [14]. Concurrent training can be defined as incorporating both resistance and endurance exercise elements within a training regime. Hickson investigated the effects of concurrent strength and endurance training for the first time [15]. There are several studies available in the literature regarding the effects of performing combined resistance-endurance exercise on cardiovascular risk factors. Hakimi, et al. showed that 8 weeks of concurrent training (resistance-endurance) significantly decreased TC, TG and LDL, and increased HDL significantly [16]. Tadibi, et al. examined the effect of 8 weeks of combined endurance and resistance training on serum leptin levels in type 2 diabetic men and showed that serum leptin concentrations decreased significantly [17]. Also, Attarzadeh-Hosseini, et al. demonstrated that 8 weeks of combined training (endurance-resistance) reduced levels of leptin, insulin, glucose, insulin resistance index and body fat percentage in the middle-aged men [10]. Nevertheless, a shortage of time is one of the commonest reasons for people that fail to do regular physical activity, that there were greater focus and attention on acute exercises, thus use of concurrent endurance and resistance exercise may also serve to improve space and time management. Azerbaijani, et al. have reported a significant reduction in leptin concentration and insulin resistance index concentration after a single session of combined aerobic and resistance exercise in men with sedentary lifestyle [18]. On the other hand, Cruz, et al. demonstrated that serum leptin did not change after one session of combined training [19].

The order of endurance and resistance exercise in the concurrent exercise session, at least in theory, could influence acute physiological responses. Drummond, et al. and Villaca Alves, et al. demonstrated that in the post-exercise $\mathrm{VO}_{2}$ was significantly greater when endurance exercise was performed before resistance exercise $[20,21]$. Against these results, Oliveira and Oliveira reported that the order of execution did not affect the Excess Post-Exercise Oxygen Consumption (EPOC) magnitude and duration [22]. In addition, Jones, et al. showed that blood cortisol and lactate concentrations were greater when endurance exercise was conducted prior to strength exercise [23].

Despite the various results of conducted studies, it is not clear if resistance and endurance are combined in the concurrent exercise session, which one could be a priority and primer is concurrent exercise to achieve better results in serum leptin level, profile lipid and insulin resistance index. Therefore, the present study aimed at investigating and comparing the effects of two methods of combined exercise (resistance-endurance and endurance-resistance) on lipid profile, leptin serum and insulin resistance index in non-athlete overweight female students.

\section{Materials \& Methods}

\section{Participants}

The present study was a semi-experimental, randomized clinical trial, conducted in accordance with a pre-test and post-test design. The study population consisted of female students of Payame Noor University of Marivan, Iran. According to entry criteria, thirty non athlete healthy young female students volunteered to participate in this study. Subjects were randomly assigned to one of the three groups: Con-

Table 1: Descriptive and functional characteristics of subjects at baseline.

\begin{tabular}{|l|l|l|l|l|l|}
\hline & CRE & CER & C & F & P-value \\
\hline Age $($ year) & $23.4 \pm 2.4$ & $22.6 \pm 2.5$ & $23.8 \pm 2.1$ & 0.014 & 0.931 \\
\hline Weight $(\mathrm{kg})$ & $73.7 \pm 6.1$ & $72.5 \pm 4.8$ & $74.1 \pm 5.1$ & 0.051 & 0.912 \\
\hline Height $(\mathrm{cm})$ & $163.3 \pm 3.8$ & $161.8 \pm 4.3$ & $164.7 \pm 5.2$ & 0.015 & 0.929 \\
\hline BMI $\left(\mathrm{kg} / \mathrm{m}^{2}\right)$ & $27.5 \pm 1.08$ & $27.6 \pm 0.75$ & $27.3 \pm 1.2$ & 0.358 & 0.712 \\
\hline VO $_{2}$ max $(\mathrm{ml} / \mathrm{kg} \cdot \mathrm{min})$ & $31.8 \pm 4.4$ & $29.2 \pm 5.3$ & $32.7 \pm 4.6$ & 0.031 & 0.901 \\
\hline HRmax (beats.min $\left.{ }^{-1}\right)$ & $191.6 \pm 11.3$ & $192.1 \pm 13.7$ & $191.3 \pm 9.6$ & 0.010 & 0.957 \\
\hline
\end{tabular}

Values are expressed as mean \pm SD. CRE: Concurrent Resistance-Endurance Group; CER: Concurrent Endurance-Resistance Group; C: control group. 
current Resistance-Endurance (CRE) exercise group ( $\mathrm{n}$ = 10), Concurrent Endurance-Resistance (CER) exercise group $(n=10)$ and control $(C)$ group $(n=10)$. Descriptive and functional characteristics of the subjects at baseline are presented in Table 1 . According to the medical information questionnaire, all subjects were healthy. Inclusion criteria comprised of age, gender, $\mathrm{BMI}$ range between $25-30 \mathrm{~kg} / \mathrm{m}^{2}$ (as overweight), lack of acute physical problems (e.g., cardiovascular and respiratory disease, skeletal injury), and lack of regular exercise training in the previous year. On the other hand, exclusion criteria included use of nutritional supplements during study, neurological or inflammatory disease and cardiac arrhythmia interfering during exercise, peripheral vascular disease, congestive heart failure, and any absolute contraindications to acute exercise and withdrawal or unwillingness to continue to participate in the study for any reasons. The Institutional Review Board of the University approved of the research protocol.

One week before the start of the exercise session, two familiarization sessions were used to determine the endurance and resistance exercise. During these sessions, the subjects were given explanations about the assessment procedures, study objectives, the possible benefits and risks, and also, subjects were familiarized with the study protocol and finally signed a consent form. Also, the menstrual cycle of subjects were controlled by a questionnaire. The questionnaire included questions regarding the regularity of the menstrual cycle and including the absence of a menstrual period, and finally, the subjects who were in the menstrual phase or have an irregular menstrual cycle or without exact statements on the time of their last menstruation were not included in the study.

In addition, the participants completed a validated food intake questionnaire, and made a 72-hour food record to determine if three groups had similar diets. Furthermore, in mentioned sessions, subjects were given instructions for the use of the body building machines and proper form of each exercise. Following the familiarization which involved exercise participants in correct lifting techniques, One Repetition Maximum (1RM) of the prescribed movements was determined using the Brzycki equation [24] and also, to determine the intensity of endurance exercise, maximum heart rate (HRmax) was measured for each person using the following formula [25].

$$
\text { HRmax }=208-(0.7 \times \text { Age })
$$

\section{Experimental design}

The concurrent exercise session consists of two exercise training: Concurrent Resistance-Endurance (CRE) exercise and Concurrent Endurance-Resistance (CER) exercise. CRE and CER groups performed the same aerobic and weight exercises and the difference between two exercise training (CRE with CER) was only in the order of resistance and endurance components. In other words, CRE was performed resistance exercise before endurance exercise, but CER was performed endurance exercise before resistance exercise. The resistance training consisted of 3 sets of 8 repetitions with $80 \%$ of $1 \mathrm{RM}$ for leg extensions, lying leg curl, triceps pushdown, bench press and lateral pull down. Recovery period were 2 and 3 minutes between sets and exercises, respectively. Also, the endurance exercise consisted of running at $70-75 \%$ of HRmax for 15 min [14]. General and specific warm-up were performed prior to training session that consisted of running with $50 \%$ of HRmax (5 $\min )$, and then perform 2 sets of 12 repetitions of the first resistance exercise at $40 \%$ of $1 \mathrm{RM}$ (10 $\mathrm{min})$, and in the end, 5 min of cool down was performed by stretching movements. Recovery time between endurance and resistance components in concurrent exercise session was 5 minutes. It should also be stated that the $C$ group do not received an intervention during study.

\section{Blood collection and analysis}

Blood samples were obtained from the antecubital vein ( $5 \mathrm{~mL}$ of whole blood) in the morning following a 12-hour overnight fast a minimum of 24 hours before and after the concurrent exercise session. For the determination of lipid profile, leptin and insulin resistance index levels, the blood samples were centrifuged for 15 minutes at $3000 \mathrm{rpm}$ at $4{ }^{\circ} \mathrm{C}$ and serum was kept frozen at $-80^{\circ} \mathrm{C}$ until analysis. TC, HDL and TG were assessed by the enzymatic colorimetric method. Analysis was performed using commercial kits (Pars Azmoon Inc., Tehran, Iran) and a selectra 2 auto-analyzer (Vital Scientific, Spankeren, Netherlands). The Intra- and inter-assay coefficients of variation were: $0.5 \%, 2 \%$ for TC, $0.6 \%, 1.6 \%$ for TG and $4.6 \%, 4.6 \%$ for $\mathrm{HDL}$, respectively. LDL cholesterol was estimated by the Friedewald formula [26]: LDL-C = TC - HDL-C -TG/5. Serum leptin concentration was measured by the ELISA method using human leptin kit (Mediagnost, Reut-lingen, Germany). The intra-assay coefficient of variation and sensitivity were: $5 \%, 0.1 \mathrm{ng} \cdot \mathrm{mL}^{-1}$, respectively. In addition, serum insulin level was assayed by the ELISA technique (sandwich) using human insulin kits (DRG-Diagnostica, $\mathrm{GmbH}$, Germany). The sensitivity was: $5.0 \mu \mathrm{IU} / \mathrm{mL}$ and the intra and inter-assay coefficient of variation were both $6.45 \%$, and, respectively. Also, the glucose concentration was measured by the enzymatic colorimetric method using commercial kits (Pars Azmoon Inc., Tehran, Iran). The inter-assay coefficient of variation and sensitivity were: $1.2 \%, 1.0 \mathrm{mg} . \mathrm{dL}^{-1}$, respectively. Insulin resistance was determined using a homeostasis model assessment (HOMA-IR) and was calculated from fasting insulin and fasting glucose as follows [27]:

HOMA-IR = fasting insulin $(\mu \mathrm{IU} / \mathrm{mL}) \times$ fasting glucose $(\mathrm{mg} / \mathrm{dL}) / 405$ 


\section{Statistical analysis}

Data normality was verified through the Shapiro-Wilk test and the homogeneity analysis of the variances through the Levene test. To evaluate the difference in within groups (pretest to posttest), Student's t-test for paired values was used and also oneway analysis of variance (one-way ANOVA) was used to compare data of the three groups with post hoc analyses conducted using the Least Significant Difference (LSD) method to locate means that were significantly different. All of the statistical procedures were processed with the SPSS version 22. A level of $P<0.05$ was considered statistically significant.

\section{Results}

In this study, the Shapiro-Wilk test indicated that data were normally distributed. Also, One-way ANOVA test demonstrated that there were no significant differences in baseline characteristics in the 3 groups. According to Table 2, the results of the present study showed that TC, TG and LDL levels significantly decreased in the two experimental groups after one session of combined training compared to the pre-test. However, no significant change was observed in HDL levels and the lipid profile of the control group. On the other hand, the results of intergroup comparisons showed that there were significant differences among the groups in other lipid

Table 2: Lipid profile changes in the control and experimental groups following single session of concurrent training.

\begin{tabular}{|c|c|c|c|c|c|c|c|c|}
\hline \multirow[t]{3}{*}{ Variables } & \multirow[t]{3}{*}{ Groups } & \multicolumn{2}{|c|}{ Time measures } & \multirow{3}{*}{$\begin{array}{l}\text { P-value } \\
\text { (Intergroup) }\end{array}$} & \multirow{2}{*}{\multicolumn{2}{|c|}{$\begin{array}{c}\text { P-value } \\
\text { (Intragroup) }\end{array}$}} & \multirow{2}{*}{\multicolumn{2}{|c|}{$\mathbf{F}$}} \\
\hline & & \multirow[t]{2}{*}{ Pretest } & \multirow[t]{2}{*}{ Posttest } & & & & & \\
\hline & & & & & Pre & Post & Pre & Post \\
\hline \multirow{3}{*}{$\begin{array}{l}\text { TC } \\
(\mathrm{mg} / \mathrm{dL})\end{array}$} & CRE & $185.6 \pm 23.6$ & $179.5 \pm 15.3$ & 0.001 & \multirow[t]{3}{*}{0.626} & \multirow[t]{3}{*}{0.032} & \multirow[t]{3}{*}{0.210} & \multirow[t]{3}{*}{6.540} \\
\hline & CER & $190.3 \pm 16.4$ & $182.7 \pm 12.5$ & 0.000 & & & & \\
\hline & C & $192.2 \pm 30.5$ & $192.6 \pm 29.4$ & 0.923 & & & & \\
\hline \multirow{3}{*}{$\begin{array}{l}\text { TG } \\
(\mathrm{mg} / \mathrm{dL})\end{array}$} & CRE & $187.6 \pm 21.4$ & $182.9 \pm 17.8$ & 0.001 & \multirow[t]{3}{*}{0.903} & \multirow[t]{3}{*}{0.024} & \multirow[t]{3}{*}{0.109} & \multirow[t]{3}{*}{7.448} \\
\hline & CER & $190.5 \pm 43.9$ & $183.4 \pm 36.1$ & 0.001 & & & & \\
\hline & C & $193.7 \pm 18.8$ & $194.6 \pm 19.7$ & 0.829 & & & & \\
\hline \multirow{3}{*}{$\begin{array}{l}\text { HDL } \\
(\mathrm{mg} / \mathrm{dL})\end{array}$} & CRE & $47.3 \pm 8.4$ & $48.4 \pm 5.4$ & 0.352 & \multirow[t]{3}{*}{0.311} & \multirow[t]{3}{*}{0.112} & \multirow[t]{3}{*}{0.481} & \multirow[t]{3}{*}{1.976} \\
\hline & CER & $46.2 \pm 4.7$ & $47.3 \pm 4.6$ & 0.281 & & & & \\
\hline & C & $42.8 \pm 4.6$ & $42.7 \pm 4.4$ & 0.963 & & & & \\
\hline \multirow{3}{*}{$\begin{array}{l}\text { LDL } \\
(\mathrm{mg} / \mathrm{dL})\end{array}$} & CRE & $100.7 \pm 20.3$ & $94.5 \pm 17.3$ & 0.003 & \multirow[t]{3}{*}{0.412} & \multirow[t]{3}{*}{0.039} & \multirow[t]{3}{*}{0.997} & \multirow[t]{3}{*}{10.214} \\
\hline & CER & $105.1 \pm 11.0$ & $98.4 \pm 8.6$ & 0.002 & & & & \\
\hline & C & $110.7 \pm 21.6$ & $110.9 \pm 24.3$ & 0.911 & & & & \\
\hline
\end{tabular}

Data presented as mean \pm SD. CRE: Concurrent Resistance-Endurance Group; CER: Concurrent Endurance-Resistance Group; C: control group. Pretest: $24 \mathrm{~h}$ before starting the exercise, posttest: $24 \mathrm{~h}$ after accomplished the exercise.

Table 3: Leptin, glucose, insulin and insulin resistance index changes in the control and experimental groups following single session of concurrent training.

\begin{tabular}{|c|c|c|c|c|c|c|c|c|}
\hline \multirow[t]{3}{*}{ Variables } & \multirow[t]{3}{*}{ Groups } & \multicolumn{2}{|c|}{ Time measures } & \multirow{3}{*}{$\begin{array}{l}\text { P-value } \\
\text { (Intergroup) }\end{array}$} & \multirow{2}{*}{\multicolumn{2}{|c|}{$\begin{array}{l}\text { P-value } \\
\text { (Intragroup) }\end{array}$}} & \multirow{2}{*}{\multicolumn{2}{|c|}{$\mathbf{F}$}} \\
\hline & & \multirow[t]{2}{*}{ Pretest } & \multirow[t]{2}{*}{ Posttest } & & & & & \\
\hline & & & & & Pre & Post & Pre & Post \\
\hline \multirow{3}{*}{$\begin{array}{l}\text { Leptin } \\
\text { (ng/dL) }\end{array}$} & CRE & $21.4 \pm 4.2$ & $19.3 \pm 3.8$ & 0.021 & & & & \\
\hline & CER & $20.9 \pm 3.9$ & $18.7 \pm 4.3$ & 0.014 & & & & \\
\hline & C & $21.8 \pm 4.7$ & $21.9 \pm 4.4$ & 0.933 & & & & \\
\hline \multirow{3}{*}{$\begin{array}{l}\text { Glucose } \\
(\mathrm{mg} / \mathrm{dL})\end{array}$} & CRE & $95.1 \pm 8.1$ & $93.9 \pm 7.8$ & 0.218 & \multirow[t]{3}{*}{0.343} & \multirow[t]{3}{*}{0.216} & \multirow[t]{3}{*}{0.843} & \multirow[t]{3}{*}{1.261} \\
\hline & CER & $97.3 \pm 7.6$ & $96.1 \pm 6.5$ & 0.146 & & & & \\
\hline & C & $95.3 \pm 8.4$ & $95.5 \pm 8.8$ & 0.826 & & & & \\
\hline \multirow{3}{*}{$\begin{array}{l}\text { Insulin } \\
(\mu \mathrm{IU} / \mathrm{mL})\end{array}$} & CRE & $7.81 \pm 2.6$ & $6.63 \pm 2.2$ & 0.039 & \multirow[t]{3}{*}{0.621} & \multirow[t]{3}{*}{0.043} & \multirow[t]{3}{*}{0.054} & \multirow[t]{3}{*}{8.624} \\
\hline & CER & $7.14 \pm 2.3$ & $5.82 \pm 1.8$ & 0.022 & & & & \\
\hline & C & $7.57 \pm 1.9$ & $7.62 \pm 2.1$ & 0.811 & & & & \\
\hline \multirow{3}{*}{$\begin{array}{l}\text { Insulin resistance } \\
(\text { HOMA-IR) }\end{array}$} & CRE & $1.84 \pm 0.6$ & $1.54 \pm 0.6$ & 0.041 & \multirow[t]{3}{*}{0.883} & \multirow[t]{3}{*}{0.028} & \multirow[t]{3}{*}{0.096} & \multirow[t]{3}{*}{9.231} \\
\hline & CER & $1.72 \pm 0.5$ & $1.38 \pm 0.4$ & 0.033 & & & & \\
\hline & C & $1.78 \pm 0.6$ & $1.80 \pm 0.7$ & 0.739 & & & & \\
\hline
\end{tabular}

Data presented as mean \pm SD. CRE: Concurrent Resistance-Endurance Group; CER: Concurrent Endurance-Resistance Group; $\mathrm{C}$ : Control group. Pretest: $24 \mathrm{~h}$ before starting the exercise, posttest: $24 \mathrm{~h}$ after accomplished the exercise. 
profile indices except for HDL $(P=0.121)$. Accordingly, the control group showed significant differences with CRE group in TC $(P=0.043)$, TG $(P=0.036)$ and LDL ( $P$ $=0.044)$ factors and compared to the CER group, these factors (TC $(P=0.043), T G(P=0.036), \operatorname{LDL}(P=0.044))$ are in a better state for the experimental groups. However, there is no significant difference between the effect of two experimental groups in terms of TC $(P=$ 0.326), TG $(P=0.619)$ and LDL $(P=0.026)$.

Furthermore, the mean changes in fasting glucose; serum leptin and insulin resistance levels for CRE, CER and $C$ groups are shown in Table 3 . Leptin serum decreased significantly in only two experimental groups after one session of combined training and no significant changes were observed in the control group. There was a significant difference in leptin serum levels in the control group compared to the CRE $(P=0.045)$ and the CER groups $(P=0.039)$ so that the leptin serum level is reduced in the experimental groups compared to the control group. On the other hand, there was no significant difference between the effects of two intervention methods on leptin serum $(P=0.414)$. The results of this study also showed that plasma glucose was not significantly different in the post-test compared to the pretest and there was no significant difference between the groups. On the other hand, insulin serum levels and insulin resistance index were significantly decreased only in the two experimental groups in the post-test compared to the pre-test. These changes were significant compared to the control group, so that the serum insulin and insulin resistance index in CER group compared to control group (insulin ( $P=0.046)$, insulin resistance index $(P=0.034)$ ) as well as CER group compared to control group (insulin (0.041)) and insulin resistance index $(P=0.029)$ were significantly reduced. However, there was no significant difference between the two experimental groups in each of the insulin factors $(P=0.312)$ and insulin resistance index $(P=0.263)$.

\section{Discussion}

The results of the present study showed that one session of combined training (resistance and endurance) reduced TC, TG and LDL in the two experimental groups significantly. However, there is no significant change in the HDL index. In addition, there were no significant changes in the lipid profile of the control group and between the two experimental groups. Consistent with the findings of the present study, Hojati, et al. in a study of 21 diabetic women reported the acute effect of combined aerobic and resistance exercise with a significant decrease in TG and TC levels 24 hours after exercise [28]. Sillanpaa, et al. in a study of 62 female (middle-aged and old) subjects, reported that endurance, strength, and combined strength and endurance training significantly decreased blood cholesterol and LDL-c levels and increased HDL levels significantly [29]. Monteiro, et al. also reported that aerobic exercise and synchronous moderate-intensity aerobic exercise significantly decreased cholesterol, VLDL, and HDL levels in the obese adolescents [30]. Contrary to the findings of the present study, Ihim, et al. in a study of 48 inactive young men, showed that the combination of intense resistance exercise (squat and chest press) and endurance exercise (jogging) had no significant effect on TG, LDL, and cholesterol levels [31]. The reasons for the inconsistency of this study are the duration, intensity, gender, and type of training. It has been reported that long-term or single-session of combined resistance and endurance exercise has beneficial effects on lipid profile. Most of these studies have been performed without regard to the order of exercises (resistance and endurance) and there is slight information in this regard. The mechanism of effect of this type of exercise on improving lipid profile is related to the enzymatic processes involved in lipid metabolism. In this regard, an increase in the enzyme activity of Lipoprotein Lipase (LPL) has been reported [32]. Sugiura, et al. argued that regular exercise activities decrease LDL, TG, TC and HDL levels by increasing the activity of LPL and Lecithin Cholesterol Acyltransferase (LCAT) [33]. However, one limitation of the present study was the lack of measurement of these enzymes. Endurance exercise by reducing fat mass and strength exercise by increasing muscle mass are both important mechanisms in increasing energy expenditure [34]. Therefore, one of the favorable effects of combined exercise is an increase in caloric expenditure and the advantageous effects on lipid profile. Therefore, these effects in the present study may be due to the caloric expenditure and subsequent lipid oxidation. On the other hand, there was no significant difference between the effects of the two combined exercise modes on lipid profile, which may be due to the caloric expenditure of the two exercise modes as the intensity; volume and duration of the trainings were equal in both groups.

In the present study, fasting glucose was not significantly different in the post-test in comparison with the pre-test groups. On the other hand, serum insulin levels and insulin resistance index were significantly decreased only in the two post-test compared to the pre-test of experimental groups, which was significant compared to the control group. However, there were no differences between the two experimental groups in any of the insulin factors and insulin resistance. Consistent with the results of the present study, Azarbayejani, et al. in the study of 10 young inactive men observed that after one session of combined endurance (treadmill running for 20 minutes with $60-70 \%$ of maximal oxygen consumption) and Resistance (with $70 \%$ of maximal repetition) exercise, the insulin resistance index had a significant decrease. However, plasma insulin levels decreased but this decrease was not significant [18]. Assarzadeh-Noushabadi and Abedi reported that combined aerobic-resistance exercise reduced insulin level and insulin resistance; however, they did not observe a 
change in fasting glucose level [35]. On the other hand, Banitalebi, et al. in a study of overweight elderly women reported that combined strength and endurance exercise had no significant effect on their insulin resistance index but decreased fasting glucose levels [36], which is inconsistent with the findings of the present study. None of the studies considered the order of strength and endurance exercise; however, there was no difference between the two types of exercise in the present study. Various mechanisms have been reported in the field of resistance and endurance exercise effect on insulin and insulin resistance such as increased protein kinase activity that activates adenosine monophosphate, glucose and mRNA transporter proteins, clearance of free fatty acid, muscle glucose access, glycogen synthase and hexokinase activity and postsynaptic insulin signals due to resistance and endurance exercise [37].

In addition, leptin levels were significantly decreased in the two experimental groups after one session of combined training compared to the control group. There was no significant difference between the effects of two experimental methods on leptin serum. Consistent with the present results, Azarbayejani, et al. by investigating sedentary young men, observed that their leptin serum levels decreased significantly after one session of endurance and resistance training [18]. Abedi, et al. also examined changes in leptin levels of obese men after endurance and strength regardless of their order. They found that leptin serum levels and insulin resistance index decreased significantly after the end of combined training [38]. Asad, et al. also examined and compared the effects of resistance, endurance, and combined training on leptin levels in male students and reported that leptin levels decreased significantly because of these exercises; however, there were no significant differences between the three training modes [39]. In a number of studies, the results are inconsistent with the present study. As Cruz, et al. examined the effect of one session of combined resistance $(65 \%$ intensity of a maximal repetition) and endurance (50 min cycling at $65 \%$ of maximal oxygen consumption on a fixed bike) training on leptin serum level of 20 overweight young girls and boys. They reported that performing one session of combined training could not significantly alter leptin serum [19]. Rosa, et al. also showed that one session of resistance and endurance training could not cause significant changes in overweight young subjects [40]. Among the possible reasons for the inconsistency of the results of this study with the present study is the intensity of different exercise and various leptin changes induced by different physiological profiles of the subjects. According to research, regular physical activity of any type of endurance, resistance or combined exercise with negative energy balance is likely to decrease leptin levels [39]. On the other hand, Jürimäe, et al. examined changes in leptin serum levels following shortterm training and there is a possibility of decreased leptin serum levels in intense short-term training [41]. Therefore, perhaps one of the reasons for the decrease in leptin serum in this study is the appropriate intensity of the combined exercise. Other possible mechanisms of the effects of intense exercise such as combined exercise on leptin depletion include decreased plasma glycogen, increased peripheral tissue glucose uptake in the presence of lactate, acidosis, and increased adrenal sympathetic stimulation [42]. In this study, considering the combination of resistance and endurance exercise and its intensity, factors such as glycogen depletion, increased sympathetic stimulation and increased peripheral tissue glucose uptake are likely to be effective mechanisms for lowering leptin levels, although the order of exercise did not show any significant difference. Other possible mechanisms for lowering leptin serum include insulin depletion, as insulin depletion has been reported to decrease leptin mRNA and leptin serum levels [43]. As mentioned earlier, the insulin levels of the subjects in this study decreased by intense administration of combined exercise; therefore, this decrease may be one of the possible causes of leptin depletion in the present study. One of the most important causes of obesity and overweight is attributable to an increase in body fat mass and increase in leptin serum concentration. Some research has shown that physical activity reduces leptin levels not only by decreasing fat mass but also by increasing leptin sensitivity [42], which may be one of the possible causes of decreased leptin levels in the present study. Of course, a great amount of research is to be done in this field to obtain comprehensive results. Studies by measuring the enzymatic changes as well as changes in hormones such as cortisol and testosterone along with the enzymatic changes are needed to investigate the mechanism of the intense effect of combined resistance and endurance exercise.

\section{Conclusion}

Generally, in the present study, the lipid profile, insulin resistance index, and leptin serum, which are important predictors of health and predictors of cardiovascular disease in overweight girls, were examined. It can be concluded that although there was no significant difference between the order of implementing the combined resistance and endurance exercise and the above-mentioned factors, performing the one-session combined resistance and endurance training in overweight girls could have favorable effects on lipid profiles, insulin resistance index and leptin serum levels. In addition to the long-term training periods, the intense performance of this type of exercise could be also considered.

\section{References}

1. Palmefors H, DuttaRoy S, Rundqvist B, Börjesson M (2014) The effect of physical activity or exercise on key biomarkers in atherosclerosis--a systematic review. Atherosclerosis 235: $150-161$. 
2. Bahrami E, Mirmoghtadaee $P$, Ardalan G, Zarkesh-Esfahani $\mathrm{H}$, Tajaddini $\mathrm{MH}$, et al. (2014) Insulin and leptin levels in overweight and normal-weight Iranian adolescents: the CASPIAN-III study. J Res Med Sci 19: 387-390.

3. Szczygielska A, Widomska S, Jaraszkiewicz M, Knera $P$, Muc K (2003) Blood lipids profile in obese or overweight patients. Ann Univ Mariae Curie Sklodowska Med 58: 343349.

4. Gruzdeva O, Borodkina D, Uchasova E, Dyleva Y, Barbarash O (2019) Leptin resistance: underlying mechanisms and diagnosis. Diabetes Metab Syndr Obes 12: 191-198.

5. Friedman JM, Halaas JL (1998) Leptin and the regulation of body weight in mammals. Nature 395: 763-770.

6. Fleisch AF, Agarwal N, Roberts MD, Han JC, Theim KR, et al. (2007) Influence of serum leptin on weight and body fat growth in children at high risk for adult obesity. J Clin Endocrinol Metab 92: 948-954.

7. Wen J, Huang Y, Lu Y, Yuan H (2019) Associations of non-high-density lipoprotein cholesterol, triglycerides and the total cholesterol/HDL-c ratio with arterial stiffness independent of low-density lipoprotein cholesterol in a Chinese population. Hypertens Res 42: 1223-1230.

8. Ajose O, Fasubaa O, Thomas K, Bolodeoku J (2002) Serum lipids and lipoprotein cholesterol profile in pregnant $\mathrm{Ni}$ gerian women. Journal of Clinical Sciences 2: 9-13.

9. Sampson UK, Fazio S, Linton MF (2012) Residual cardiovascular risk despite optimal LDL cholesterol reduction with statins: the evidence, etiology, and therapeutic challenges. Curr Atheroscler Rep 14: 1-10.

10. Attarzadeh Hosseini SR, Mir E, Hejazi K, Mir Sayeedi M (2015) The Effect of eight weeks combined training on some insulin resistance markers in middle-aged men. Medical Journal of Mashhad University of Medical Sciences 58: 129-136.

11. Ormazabal V, Nair S, Elfeky O, Aguayo C, Salomon C, et al. (2018) Association between insulin resistance and the development of cardiovascular disease. Cardiovasc Diabetol 17: 122.

12. Swarbrick MM, Havel PJ (2008) Physiological, pharmacological, and nutritional regulation of circulating adiponectin concentrations in humans. Metab Syndr Relat Disord 6: 87102.

13. Tian D, Meng J (2019) Exercise for Prevention and Relief of Cardiovascular Disease: Prognoses, Mechanisms, and Approaches. Oxidative Medicine and Cellular Longevity 2019.

14. Sheikholeslami-Vatani D, Siahkouhian M, Hakimi M, Ali-Mohammadi $M$ (2015) The effect of concurrent training order on hormonal responses and body composition in obese men. Science \& Sports 30: 335-341.

15. Hickson RC (1980) Interference of strength development by simultaneously training for strength and endurance. Eur $\mathrm{J}$ Appl Physiol 45: 255-263.

16. Hakimi M, Sheikholeslami-Vatani D, Ali-Mohammadi M (2015) Effect of concurrent training with ingested of L-carnitine supplementation on hormonal changes, lipid profile and body composition in obese men. Urmia Medical Journal 26: 185-193.

17. Tadibi V, Behpour N, Rahimi M, Rashidi S, Delbari M, et al. (2015) Comparison of the effect of 8 weeks of aerobic and combined training on serum levels of leptin and glucose in type 2 diabetic men. Journal of Gorgan University of Medical Sciences 17: 6-13.
18. Azarbayejani M, Abedi B, Piri M, Rasaie M (2012) The Effects of a Single Session of Combined Aerobic and Resistance Exercise on Leptin Levels and Insulin Resistance Index in Sedentary Men. Qom University Medical Science Journal 6: 46-54.

19. Cruz IS, Rosa G, Valle V, Mello DBd, Fortes M, et al. (2012) Efeitos agudos do treinamento concorrente sobre os níveis séricos de leptina e cortisol em adultos jovens sobrepesados. Revista Brasileira de Medicina do Esporte 18: 81-86.

20. Drummond MJ, Vehrs PR, Schaalje GB, Parcell AC (2005) Aerobic and resistance exercise sequence affects excess postexercise oxygen consumption. J Strength Cond Res 19: 332-337.

21. Alves J, Saavedra F, Simão R, Novaes J, Rhea MR, et al. (2012) Does aerobic and strength exercise sequence in the same session affect the oxygen uptake during and postexercise? J Strength \& Cond Res 26: 1872-1878.

22. Oliveira NL, Oliveira J (2011) Excess postexercise oxygen consumption is unaffected by the resistance and aerobic exercise order in an exercise session. J Strength Cond Res 25: $2843-2850$.

23. Jones TW, Howatson G, Russell M, French DN (2017) Effects of strength and endurance exercise order on endocrine responses to concurrent training. Eur J Sports Sci 17: 326-334.

24. Brzycki M (1993) Strength testing-predicting a one-rep max from reps-to-fatigue. Journal of Physical Education, Recreation \& Dance 64: 88-90.

25. Franckowiak SC, Dobrosielski DA, Reilley SM, Walston JD, Andersen RE (2011) Maximal heart rate prediction in adults that are overweight or obese. J Strength Cond Res 25: $1407-1412$.

26. Friedewald WT, Levy RI, Fredrickson DS (1972) Estimation of the concentration of low-density lipoprotein cholesterol in plasma, without use of the preparative ultracentrifuge. Clin Chem 18: 499-502.

27. Dumortier M, Brandou F, Perez-Martin A, Fedou C, Mercier $J$, et al. (2003) Low intensity endurance exercise targeted for lipid oxidation improves body composition and insulin sensitivity in patients with the metabolic syndrome. Diabetes Metab 29: 509-518.

28. Hojjati Z, Shahsavari S (2015) Acute effects of aerobic and combined exercise on serum lipid profile in type ii diabetic females. Iranian Journal of Health Sciences 3: 31-37.

29. Sillanpää E, Laaksonen DE, Häkkinen A, Karavirta L, Jensen B, et al. (2009) Body composition, fitness, and metabolic health during strength and endurance training and their combination in middle-aged and older women. Eur J Appl Physiol 106: 285-296.

30. Monteiro PA, Chen KY, Lira FS, Saraiva BTC, Antunes BMM, et al. (2015) Concurrent and aerobic exercise training promote similar benefits in body composition and metabolic profiles in obese adolescents. Lipids Health Dis 14: 153.

31. Ihim A, Meludu S, Obiodinukwe C, Okeke C, Oluboyo A, et al. (2015) Effect of short-term exercise on serum cortisol and lipid profile in young male of College of Health Sciences, Nnamdi Azikiwe University, Nnewi Campus. Indian Journal of Basic and Applied Medical Research 4: 213-218.

32. Valle VSd, Mello DBd, Fortes MdSR, Dantas EHM, Mattos Mad (2010) Effect of diet and indoor cycling on body composition and serum lipid. Arq Bras Cardiol 95: 173-178.

33. Sugiura $H$, Sugiura $H$, Kajima K, Mirbod SM, Iwata $H$, et al. 
(2002) Effects of long-term moderate exercise and increase in number of daily steps on serum lipids in women: randomised controlled trial [ISRCTN21921919]. BMC Women's Health 2: 3.

34. Hakimi M, Sheikholeslami-Vatani D, Alimohamadi M (2015) Comparing the effect of 8-week resistance training with concurrent (resistance- massage) on leptin serum, lipid profile and body composition in overweight young male. Sport Physiology 7: 15-32.

35. Assarzade Noushabadi M, Abedi B (2012) Effects of combination training on insulin resistance index and some inflammatory markers in inactive men. The Horizon of Medical Sciences 18: 95-105.

36. Banitalebi E, Hoseinzadeh A, Mardanpour-Shahrekordi Z, Amani-Shalamzari S (2015) Effect of three methods of combined training (strength and endurance) on serum adiponectin levels and insulin resistance in overweight elderly women. Scientific Journal of Kurdistan University of Medical Sciences 20: 30-40.

37. Abedi B, Azarbayjani MA, Peeri M, Rasaee MJ (2011) The effect of a single session of resistance training on serum adiponectin level and insulin resistance index in sedentary men. Arak Medical University Journal 14: 53-62.

38. Abedi B, Akbarpour Beni M, Assar Zadeh Noosh Abadi M, Khorshidi D (2016) Effect of concurrent training on leptin, $\mathrm{C}$ - reactive protein and HOMA-IR in overweight men. Biomedicine and Nursing 2: 91-98.

39. Asad M, Ghare M, Ferdowsi MH (2012) The effect of endurance, resistance and concurrent trainings on plasma leptin levels of male students. Journal of Sport Biosciences 13: 107-123.

40. Dantas EH, Cruz I, De Sa RF, Rosa G, De Mello DB (2012) Effect of concurrent training on serum leptin concentrations in overweight young adults. International Sport Medicne Journal 13: 69-75.

41. Jürimäe J, Jürimäe T (2005) Leptin responses to short term exercise in college level male rowers. Br J Sports Med 39: 6-9.

42. Shahidi F, Pirhadi S (2014) The effect of physical exercise and training on serum leptin levels. Razi Journal of Medical Sciences 21: 1-14.

43. Cohen B, Novick D, Rubinstein M (1996) Modulation of insulin activities by leptin. Science 274: 1185-1188. 